\title{
Ciliated muconodular papillary tumor with a growing cavity shadow that mimicked colorectal metastasis to the lung: a case report
}

\author{
Kotaro Murakami ${ }^{1}$, Yojiro Yutaka ${ }^{1 *} \mathbb{D}$, Naoki Nakajima ${ }^{2}$, Akihiko Yoshizawa ${ }^{2}$ and Hiroshi Date ${ }^{1}$
}

\begin{abstract}
Background: Ciliated muconodular papillary tumor (CMPT) is a rare papillary nodule tumor with benign and malignant characteristics that occurs in the peripheral lung.

Case presentation: A 70-year-old woman who underwent right hemicolectomy for colorectal cancer (CRC; pT3NOMO, p-stage II) 2 years prior, presented with a sub-centimeter growing cavity shadow on chest computed tomography (CT), which was suspected to be a CRC metastasis. Because positron emission tomography CT suggested there was no other site suspicious of recurrence, thoracoscopic resection with preoperative pleural dye marking was planned to remove the small lesion, which seemed to be hardly palpable on CT. Immediately after pleural dye marking adjacent to the lesion using cone beam $\mathrm{CT}$ in the hybrid operating room, thoracoscopic wedge resection was performed and the tumor was finally diagnosed as CMPT, characterized by the papillary growth of mucus-producing cells in the alveoli.
\end{abstract}

Conclusion: We resected the non-palpable small lung lesions following preoperative marking using cone-beam CT in the hybrid operating room. This case highlights a rare cavitary CT image of a CMPT mimicking a metastatic lung tumor from colorectal cancer.

Keyword: Ciliated muconodular papillary tumor, Cavity shadow, Metastatic lung tumor, Non-palpable tumor

\section{Background}

Ciliated muconodular papillary tumor (CMPT) is a rare peripheral lung tumor, characterized by the papillary growth of ciliated columnar, mucous, and basal cells. Our case was unusual because a growing cavitary lesion detected by computed tomography (CT) initially led us to suspect a colorectal cancer (CRC) metastasis.

\section{Case presentation}

A 70-year-old woman with a 45-year smoking history, who had undergone colectomy for CRC (pT3NOM0, p-stage II, well-differentiated tubular adenocarcinoma

\footnotetext{
*Correspondence: yutaka7@kuhp.kyoto-u.ac.jp

1 Department of Thoracic Surgery, Kyoto University Hospital, 54

KawaharachoSakyo-ku, ShogoinKyoto 606-8507, Japan

Full list of author information is available at the end of the article
}

[tub1, pT3/SS, ly0, v0, pH0]). 2 years prior, presented with a CT nodule shadow in her right lower pulmonary lobe that had grown from $0.2 \mathrm{~cm}$ at her right hemicolectomy (Fig. 1a) to $0.3 \mathrm{~cm}$ at 12 months, and to $0.5 \mathrm{~cm}$ at 14 months postoperatively (Fig. 1b). The serum levels of tumor markers were within their normal ranges; CEA, 2.9 ng/mL; CA19-9, $6.8 \mathrm{U} / \mathrm{mL}$; CA125, $4.0 \mathrm{U} / \mathrm{mL}$. Because this growing cavitary lesion with a slightly irregular wall thickness suggested CRC metastasis, a thoracoscopic resection was performed.

As the lesion was barely palpable, preoperative marking was required. Although the dye material was radiolucent, the tip of the catheter used for dye marking was radiopaque. After confirming the positional relationship between the tumor and the tip of the catheter by using cone-beam $\mathrm{CT}$ in the hybrid operating room, dye marking with indigo-carmine dye $(0.3 \mathrm{~mL})$ by bronchoscopy 

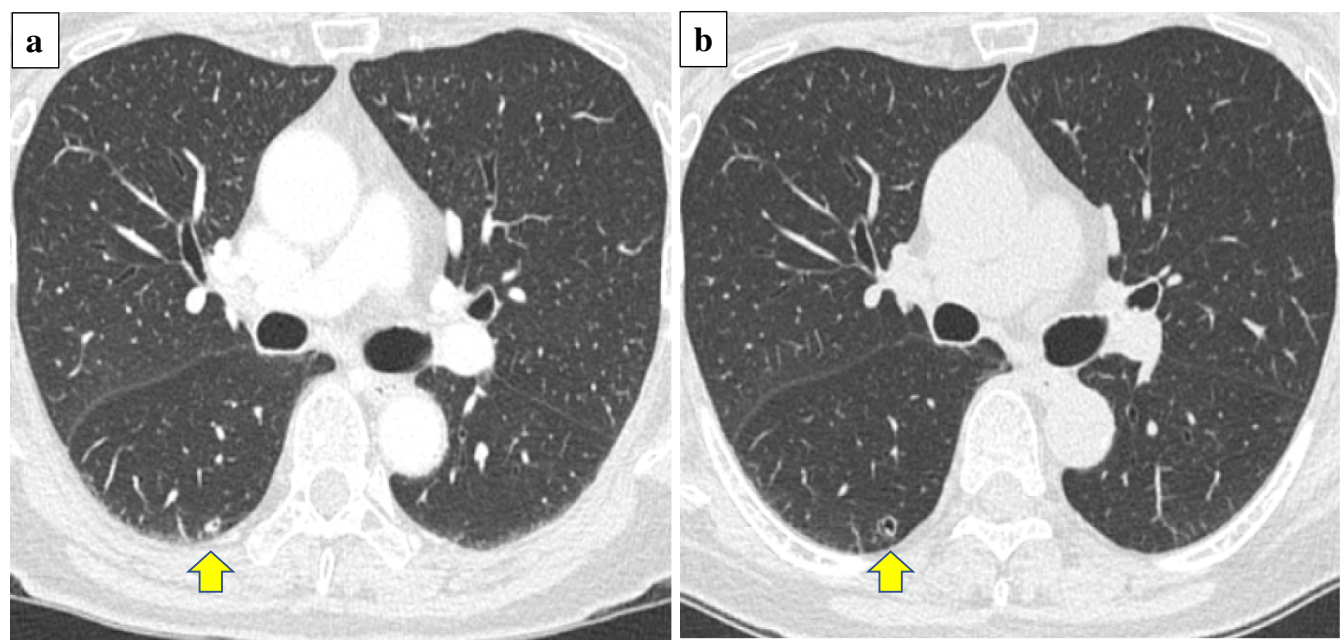

Fig. 1 Serial CT findings of a ciliated muconodular papillary tumor (CMPT) at a colectomy performed 14 months prior and $\mathbf{b}$ thoracoscopic surgery. Yellow arrows indicate tumor growth from the nodule to a cavitary lesion suspicious of metastasis of colorectal cancer

was performed at a point around $5 \mathrm{~mm}$ cranial to the tumor. Preoperative marking took 6 min with two CT inspections (Fig. 2a, b). Intraoperatively, the tumor had no gross pleural changes, but because it was slightly palpable at $5 \mathrm{~mm}$ caudal from the dyed site, we performed a wedge resection (Fig. 2c). Intraoperative frozen sections revealed fibrotic tissues with no apparent malignant cells, which did not match the CRC tissue. Permanent sections showed proliferating papillary cells with cilia adjacent to the bronchi and mucous glands around the cystic wall; the alveolar structure was intact and was composed of normal epithelial cells, with no atypical cells (Fig. 3a, b). Immunohistochemically, the lesion was positive for cytokeratin-7 (CK7), focal positive for thyroid transcription factor-1 (TTF-1), and negative for cytokeratin-20 (CK20) and caudal type homeobox-2 (CDX2), which ruled out CRC metastasis (Fig. 3c, d). We therefore diagnosed the tumor as CMPT. The patient has remained recurrence-free for 7 months.

\section{Discussion}

Since CMPT was first reported in 2002 by Ishikawa et al., only 60 cases have been reported and it has not been categorized by the World Health Organization [1, 2] (Table 1). CMPT reportedly occurs more frequently in women (males:females, 1:1.2), and has no correlation with smoking history. Although it usually presents as a peripheral nodule with ground glass opacity (GGO) on

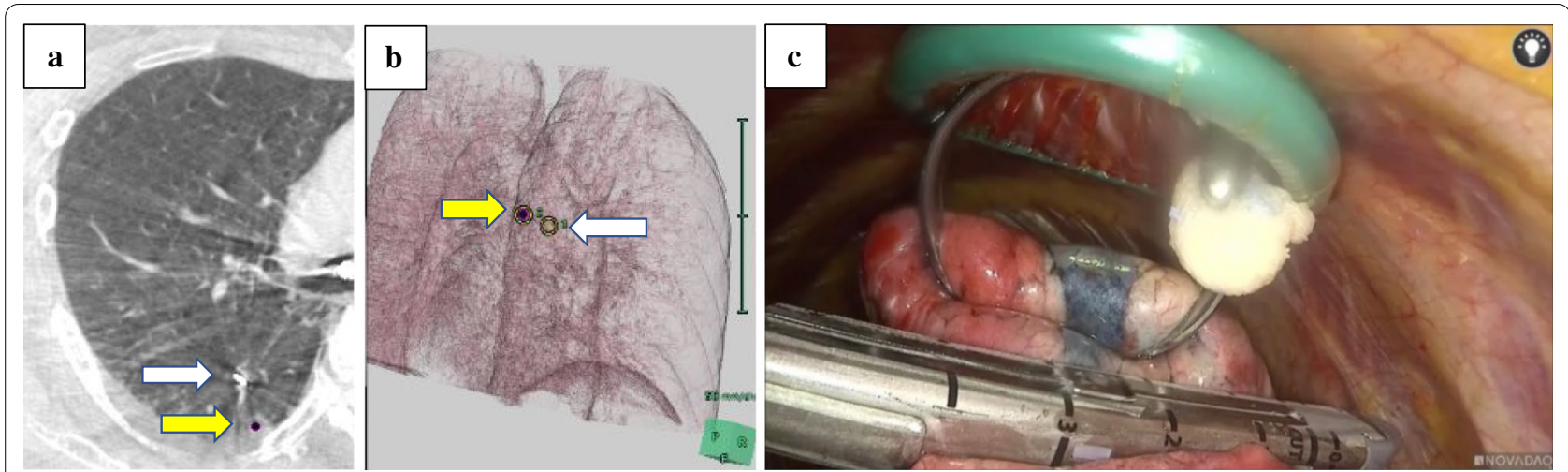

Fig. 2 Intraoperative findings of thoracoscopic wedge resection using cone beam computed tomography (CT) in a hybrid surgical theater. a Intraoperative CT image. The yellow arrow indicates the tumor shadow position, and the white arrow denotes the tip of the injection catheter advanced through a working channel of a flexible bronchoscopy. $\mathbf{b}$ Three-dimensional positional relationship between the tumor (yellow arrow) and the marking spot on the pleural surface (white arrow), which was reconstructed in a surgical room. c Wedge resection was performed using a linear stapler 

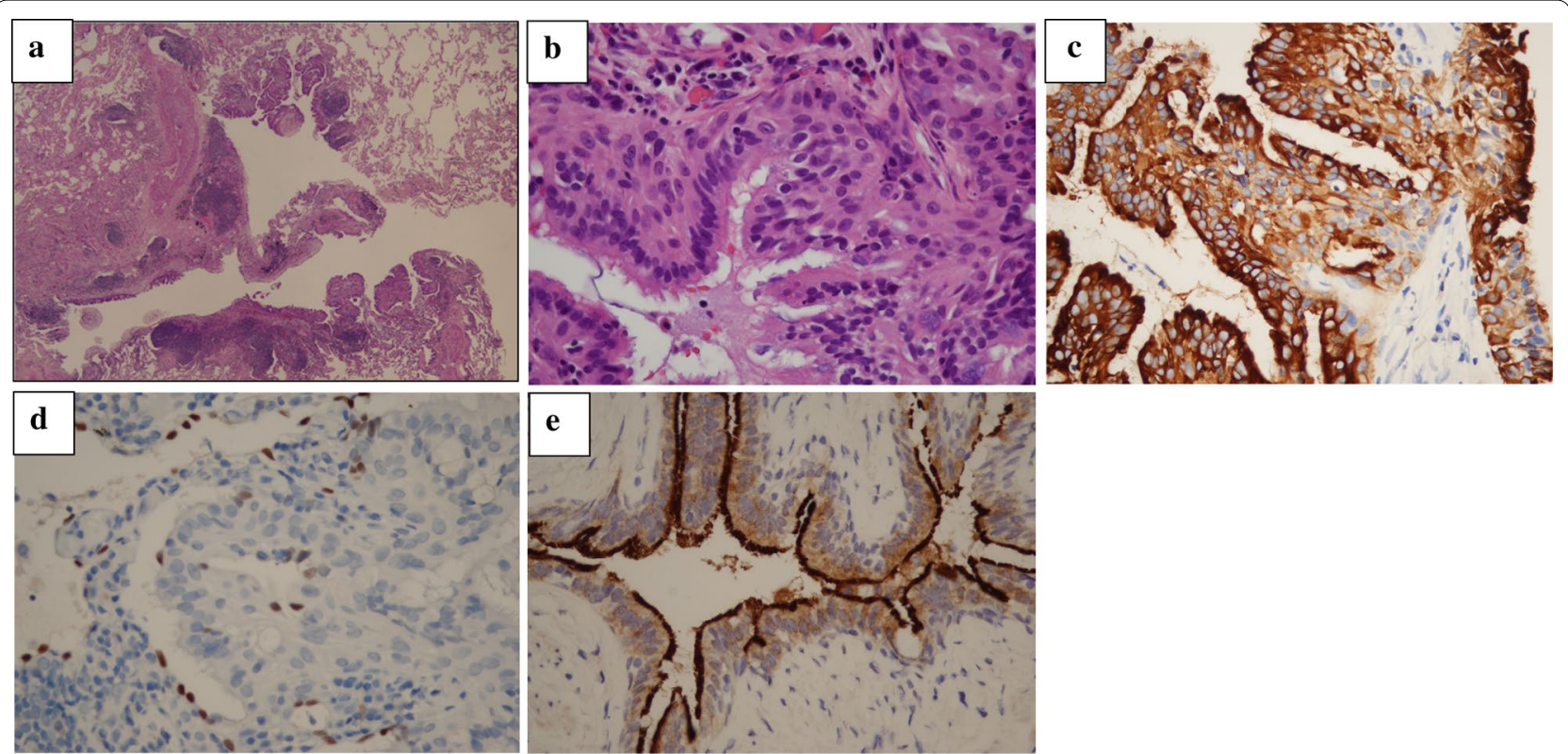

Fig. 3 a Cyst cavity showing proliferation of papillary cells with cilia adjacent to the bronchi and mucous glands around the cystic wall (HE, $\times 20)$. b Mucous gland suggests alveolar structures were intact and composed of normal epithelial cells with no atypical cells $(H E, \times 200)$ in the resected tumor. c CK7 staining was strong and diffuse in most epithelial cells $(\times 400)$. d Focal TTF- 1 staining in occasional ciliated cells $(\times 400)$. e Cilia cells were positive for BRAF staining $(\times 400)$

CT (median size, $10 \mathrm{~mm}$; range, $4-45 \mathrm{~mm}$ ), only $13 \%$ of reported cases show central cavitation on CT, and a recent case series $(n=16)$ to assess thin-section CT features of CMPT showed no cases of cavity formation [3].

Our case presenting with a growing cavity shadow was radiographically suspected to be CRC metastasis, because necrotic components, known as dirty necrosis, which suggest a colorectal origin, were considered to be drained through the airway [4]. However, the specimen was CK7 + /TTF1+/CDX2-/CK20-, which indicated that it was not a metastasis. CMPT typically shows distinct papillary growth of a mixture of ciliated columnar, mucous, and basal cells, often with central mucin accumulation, focal fibrosis, and a disrupted alveolar framework, which correlates with cavitation on CT. Because differential diagnosis of CMPT includes adenocarcinoma with cilia formation, mucinous adenocarcinoma, mucoepidermoid carcinoma, peribronchiolar metaplasia, and glandular papilloma, intraoperative diagnosis of these lesions from a small specimen can be challenging. To our knowledge, only two CMPT cases have been diagnosed intraoperatively, both of which by facilities that had previously diagnosed CMPT [5]. Histopathologically, our CMPT was diagnosed as a benign lesion; however, some reports suggest it to be a precursor of adenocarcinoma because they had confirmed BRAF, EGFR, and ALK mutations, which occur early in lung adenocarcinogenesis. In our case, BRAF immunostaining was positive for only cilia cell, and the tumor itself was not stained (Fig. 3e); however, other studies reported that epithelial cells and cytoplasm had been stained [6, 7]. Because CMPT is rare and lacks accumulated studies, whether these molecular findings support CMPT being an adenocarcinoma precursor remains unclear.

Regarding optimal resection, in a thoracoscopic setting without any preoperative marking, accurate localization of the 6-mm tumor located apart from the pleura seemed to be difficult $[8,9]$. Generally, preoperative marking methods for small lesions include CT-guided marking and bronchoscopic marking. However, CT-guided marking with hook wires can cause pneumothorax, bleeding, and potentially fatal air embolism in about $1.3 \%$ of cases [10]. On the other hand, bronchoscopic marking has a lower risk of complications compared to the former method, but if the lesion is too faint to be identified using fluoroscopy or when it located deep to the pleura, the marking procedure itself tends to be difficult because the positional relationship between the marking position and the tumor cannot be grasped. In this case, because the lesion seemed to be difficult to detect by fluoroscopy and could not be palpated because of the small size and a morphology of the cavity, we planned a more reliable and less invasive preoperative marking following resection using a cone-beam CT in a hybrid operating room. A quarter of reported CMPT cases were treated with lobectomies despite the small lesion size. Despite the potential 
Table 1 Clinical features of reported CMPT cases

\begin{tabular}{|c|c|c|c|c|c|c|c|c|}
\hline Author & Age & Sex & Location & CT finding & $\begin{array}{l}\text { Size } \\
(\mathrm{mm})\end{array}$ & $\begin{array}{l}\text { Operative } \\
\text { procedure }\end{array}$ & Intraoperative pathological diagnosis & $\begin{array}{l}\text { Outcome } \\
\text { (months) }\end{array}$ \\
\hline Ishikawa(2002) & 50 & $\mathrm{~F}$ & RUL & Nodule & 15 & L & $\mathrm{n} / \mathrm{a}$ & 120 \\
\hline Harada (2008) & 62 & M & LLL & Nodule & 9 & W & $\mathrm{n} / \mathrm{a}$ & $n / a$ \\
\hline \multirow[t]{2}{*}{ Sato (2010) } & 67 & M & RUL & Nodule with GGO & 5 & W & Low-grade malignant tumor & 10 \\
\hline & 59 & $\mathrm{~F}$ & RLL & GGO with cavity & 7 & W & CMPT & 18 \\
\hline Ishikawa (2013) & 57 & $\mathrm{~F}$ & LLL & Nodule with cavity & 11 & L & Adenocarcinoma & 6 \\
\hline Yuki (2013) & 70 & $\mathrm{~F}$ & RLL & Nodule & 8 & W & $\mathrm{n} / \mathrm{a}$ & $\mathrm{n} / \mathrm{a}$ \\
\hline Hata (2013) & 76 & $\mathrm{~F}$ & LUL & Nodule & 7 & L & Malignancy & 24 \\
\hline Chuang (2014) & 68 & M & RLL & Nodule & 12 & W & Adenocarcinoma & 48 \\
\hline \multirow[t]{10}{*}{ Kamata (2015) } & 61 & M & RUL & Nodule & 10 & W & $\mathrm{n} / \mathrm{a}$ & 76 \\
\hline & 60 & $\mathrm{~F}$ & LLL & Nodule & 15 & W & $\mathrm{n} / \mathrm{a}$ & 33 \\
\hline & 78 & M & RLL & Nodule & 9 & S & $\mathrm{n} / \mathrm{a}$ & 66 \\
\hline & 63 & M & RLL & Nodule & 11 & L & $\mathrm{n} / \mathrm{a}$ & 63 \\
\hline & 75 & M & LLL & Nodule & 6 & W & $\mathrm{n} / \mathrm{a}$ & 44 \\
\hline & 62 & $\mathrm{~F}$ & LLL & Nodule with cavity & 13 & W & $\mathrm{n} / \mathrm{a}$ & 45 \\
\hline & 57 & M & RLL & Nodule & 12 & W & $\mathrm{n} / \mathrm{a}$ & 7 \\
\hline & 56 & M & RLL & Nodule & 11 & W & $\mathrm{n} / \mathrm{a}$ & 4 \\
\hline & 66 & M & LLL & Nodule & 7 & W & $\mathrm{n} / \mathrm{a}$ & 88 \\
\hline & 61 & $\mathrm{~F}$ & RLL & Nodule & 6 & W & $\mathrm{n} / \mathrm{a}$ & 2 \\
\hline Chu (2015) & 56 & M & LUL & Nodule & 11 & S & Mucinous adenocarcinoma & 5 \\
\hline Lau (2016) & 19 & $\mathrm{~F}$ & RLL & Nodule with cavity & 13 & W & Mucinous neoplasm & $\mathrm{n} / \mathrm{a}$ \\
\hline \multirow[t]{5}{*}{ Ishikawa (2016) } & 66 & M & RUL & Nodule & 13 & L & Mucinous cystic neoplasm & 58 \\
\hline & 82 & $\mathrm{~F}$ & LLL & Nodule & 10 & W & No malignancy & 55 \\
\hline & 77 & M & LLL & Mass with cavity & 45 & L & Adenocarcinoma suspected & 48 \\
\hline & 70 & M & RLL & GGO & 35 & W & CMPT & 19 \\
\hline & 67 & $\mathrm{~F}$ & RLL & Nodule & 5 & W & No malignancy & 28 \\
\hline \multirow[t]{4}{*}{ Liu (2016) } & 60 & M & RLL & Nodule & 12 & W & $\mathrm{n} / \mathrm{a}$ & 7 \\
\hline & 83 & $\mathrm{~F}$ & RML & Nodule & 4 & L & No malignancy & $\mathrm{n} / \mathrm{a}$ \\
\hline & 81 & $\mathrm{~F}$ & $\mathrm{n} / \mathrm{a}$ & Nodule & 4 & W & No malignancy & $\mathrm{n} / \mathrm{a}$ \\
\hline & 71 & $\mathrm{~F}$ & LUL & Nodule with GGO & 12 & W & Glandular papilloma & 120 \\
\hline \multirow[t]{5}{*}{ Kon (2016) } & 80 & M & LLL & Nodule with cavity & 7 & W & $\mathrm{n} / \mathrm{a}$ & 29 \\
\hline & 67 & M & RLL & Nodule & 10 & W & $\mathrm{n} / \mathrm{a}$ & 25 \\
\hline & 66 & M & RLL & Nodule with cavity & 13 & L & $\mathrm{n} / \mathrm{a}$ & 14 \\
\hline & 73 & $\mathrm{~F}$ & LUL & Nodule with cavity & 9 & W & n/a & 5 \\
\hline & 70 & $\mathrm{~F}$ & RLL & Nodule & 8 & W & $\mathrm{n} / \mathrm{a}$ & 48 \\
\hline Taguchi (2017) & 84 & $\mathrm{~F}$ & RLL & Nodule & 8 & W & $\mathrm{n} / \mathrm{a}$ & 10 \\
\hline Segawa(2017) & 42 & M & LLL & Nodule with cavity & 11 & L & Mucinous adenocarcinoma & 24 \\
\hline $\operatorname{Jin}(2017)$ & 59 & $\mathrm{~F}$ & RLL & Nodule with cavity & 8 & L & Atypical glandular lesion & 6 \\
\hline \multirow[t]{4}{*}{ Udo (2017) } & $\begin{array}{l}\text { n/a } \\
\text { (median 67) }\end{array}$ & $\mathrm{F}$ & $\mathrm{n} / \mathrm{a}$ & $\mathrm{n} / \mathrm{a}$ & $\begin{array}{l}\mathrm{n} / \mathrm{a} \\
\text { (median 11) }\end{array}$ & $\begin{array}{l}\mathrm{n} / \mathrm{a} \\
(\mathrm{L} 3, \mathrm{~S} 1)\end{array}$ & $\mathrm{n} / \mathrm{a}$ & $\mathrm{n} / \mathrm{a}$ \\
\hline & $\mathrm{n} / \mathrm{a}$ & $\mathrm{F}$ & $\mathrm{n} / \mathrm{a}$ & $\mathrm{n} / \mathrm{a}$ & $\mathrm{n} / \mathrm{a}$ & $\mathrm{n} / \mathrm{a}$ & $\mathrm{n} / \mathrm{a}$ & $\mathrm{n} / \mathrm{a}$ \\
\hline & $\mathrm{n} / \mathrm{a}$ & $\mathrm{F}$ & $\mathrm{n} / \mathrm{a}$ & $\mathrm{n} / \mathrm{a}$ & $\mathrm{n} / \mathrm{a}$ & $\mathrm{n} / \mathrm{a}$ & $\mathrm{n} / \mathrm{a}$ & $\mathrm{n} / \mathrm{a}$ \\
\hline & $\mathrm{n} / \mathrm{a}$ & $\mathrm{F}$ & $\mathrm{n} / \mathrm{a}$ & $\mathrm{n} / \mathrm{a}$ & $\mathrm{n} / \mathrm{a}$ & $\mathrm{n} / \mathrm{a}$ & $\mathrm{n} / \mathrm{a}$ & $\mathrm{n} / \mathrm{a}$ \\
\hline Kita (2018) & 67 & $\mathrm{~F}$ & LLL & Nodule & 7 & W & No malignancy & 24 \\
\hline Miyai (2018) & 67 & $\mathrm{~F}$ & RML & Nodule with GGO & 20 & W & $\mathrm{n} / \mathrm{a}$ & 4 \\
\hline \multirow[t]{2}{*}{ Shen (2019) } & 58 & M & RLL & Nodule & 11 & L & Papillary carcinoma & $\mathrm{n} / \mathrm{a}$ \\
\hline & 64 & $\mathrm{~F}$ & LLL & Nodule & 8.5 & W & Adenocarcinoma & $\mathrm{n} / \mathrm{a}$ \\
\hline Matsuoka (2019) & 76 & $\mathrm{~F}$ & RLL & Nodule & 10 & W & Mucinous adenocarcinoma & 24 \\
\hline Yao (2019) & 67 & $\mathrm{~F}$ & LUL & Nodule & 12 & S & No malignancy & 10 \\
\hline Cheung (2019) & 61 & M & RLL & Nodule with cavity & 10 & $\mathrm{~L}$ & Mucinous adenocarcinoma & 12 \\
\hline
\end{tabular}


Table 1 (continued)

\begin{tabular}{|c|c|c|c|c|c|c|c|c|}
\hline Author & Age & Sex & Location & CT finding & $\begin{array}{l}\text { Size } \\
(\mathrm{mm})\end{array}$ & $\begin{array}{l}\text { Operative } \\
\text { procedure }\end{array}$ & Intraoperative pathological diagnosis & $\begin{array}{l}\text { Outcome } \\
\text { (months) }\end{array}$ \\
\hline \multirow[t]{2}{*}{ Shao (2019) } & 58 & $\mathrm{~F}$ & LLL & Nodule with GGO & 8 & W & $\mathrm{n} / \mathrm{a}$ & $\mathrm{n} / \mathrm{a}$ \\
\hline & 66 & $\mathrm{~F}$ & RLL & Nodule & 6 & W & $\mathrm{n} / \mathrm{a}$ & $\mathrm{n} / \mathrm{a}$ \\
\hline Our case & 70 & $\mathrm{~F}$ & RLL & Nodule with cavity & 6 & W & No malignancy & 7 \\
\hline
\end{tabular}

We did not add the 16 cases reported by Onishi et al. to the table at this time because the details of the clinical findings of the patients had not been described in the text

$M$ male, $F$ : female, $R U L$ right upper lobe, $R M L$ right middle lobe, $R L L$ right lower lobe, $L U L$ left upper lobe, $L L L$ left lower lobe, $G G O$ ground glass opacity, $L$ lobectomy, $S$ segmental resection, $W$ wedge resection, CMPT ciliated muconodular papillary tumor, $n / a$ not applicable

malignancy of CMPT, no recurrence or metastasis has been reported for up to 10 years by wedge resection, and thus additional resection was not planned after the final diagnosis of CMPT.

\section{Conclusions}

CMPT can present as GGO, nodules, or (rarely) cavitary formation with irregular wall thickness mimicking a metastasis. Its pathology is not clearly defined, and it may have benign or malignant properties, depending on the molecular alterations. Although no recurrence or metastasis has been reported, CMPT should be resected with sufficient margins.

\section{Abbreviations}

CMPT: Ciliated muconodular papillary tumor; CT: Computed tomography; CRC : Colorectal cancer; CK7: Cytokeratin-7; CDX2: Caudal type homeobox-2; GGO: Ground glass opacity; EGFR: Epidermal growth factor receptor; ALK: Anaplastic lymphoma kinase.

\section{Acknowledgements}

We thank H. Nikki March, PhD, from Edanz Group (www.edanzediting.com/ac) for editing a draft of this manuscript.

\section{Authors' contributions}

$K M$ and $Y Y$ wrote the manuscript. HD supervised the case. All other authors reviewed the manuscript. All authors read and approved the final manuscript.

\section{Funding}

The authors received no financial support for the research, authorship, and/or publication of this article.

\section{Availability of data and materials}

Data sharing is not applicable to this article as no datasets were generated or analyzed during the current study.

\section{Ethics approval and consent to participate}

Not applicable.

\section{Consent for publication}

Written informed consent was obtained from the patient for the publication of this report.

\section{Competing interests}

The authors declare that they have no competing interests.

\section{Author details}

1 Department of Thoracic Surgery, Kyoto University Hospital, 54 KawaharachoSakyo-ku, ShogoinKyoto 606-8507, Japan. ${ }^{2}$ Diagnostic Pathology, Department of Thoracic Surgery, Kyoto University Hospital, Kyoto, Japan.

Received: 30 June 2020 Accepted: 19 September 2020

Published online: 29 September 2020

\section{References}

1. Shen L, Lin J, Ren Z, Wang B, Zhao K, Yunlong Lu, et al. Ciliated muconodular papillary tumor of the lung: report of two cases and review of the literature. J Surg Case Rep. 2019;8:1-3.

2. Yen-Wen Lu, Yeh Y-C. Ciliated muconodular papillary tumors of the lung. Arch Pathol Lab Med. 2019;143:135-9.

3. Onishi Y, Kusumoto M, Motoi N, Watanabe H, Watanabe SI. Ciliated muconodular papillary tumor of the lung: thin-section CT findings of 16 cases. AJR Am J Roentgenol. 2020;22:1-5.

4. Marchevsky AM, Gupta R, Balzer B. Diagnosis of metastatic neoplasms: a clinicopathologic and morphologic approach. Arch Pathol Lab Med. 2010:134:194-206.

5. Sato S, Koike T, Homma K, Yokoyama A. Ciliated muconodular papillary tumour of the lung: a newly defined low-grade malignant tumour. Interact Cardiovasc Thorac Surg. 2010;11:685-7.

6. Liu L, Aesif SW, Kipp BR, Voss JS, Daniel S, Aubry MC, et al. Ciliated muconodular papillary tumors of the lung can occur in Western patients and show mutations in BRAF and AKT1. Am J Surg Pathol. 2016;40:1631-6.

7. Udo E, Furusato B, Sakai K, Prentice LM, Tanaka T, Kitamura Y, et al. Ciliated muconodular papillary tumors of the lung with KRAS/BRAF/AKT1 mutation. Diagn Pathol. 2017;12:62.

8. Yutaka Y, Sato T, Matsushita K, Aiba H, Muranishi Y, Sakaguchi Y, et al. Three-dimensional navigation for thoracoscopic sublobar resection using a novel wireless marking system. Semin Thorac Cardiovasc Surg. 2018;30:230-7

9. Yutaka Y, Sato T, Zhang J, Matsushita K, Aiba H, Muranishi Y, et al. Localizing small lung lesions in video-assisted thoracoscopic surgery via radiofrequency identification marking. Surg Endosc. 2017:31:3353-62.

10. Kondo T, Tokunaga Y, Saito M, Nakagawa T. Two cases of air embolism during percutaneous pulmonary marking under computed tomography guidance. JPN J Chest Surg. 2012;26:31-5.

\section{Publisher's Note}

Springer Nature remains neutral with regard to jurisdictional claims in published maps and institutional affiliations. 